\title{
DArT markers: diversity analyses, genomes comparison, mapping and integration with SSR markers in Triticum monococcum Hai-Chun Jing*1,4, Carlos Bayon ${ }^{1}$, Kostya Kanyuka1 ${ }^{1}$, Simon Berry², Peter Wenzl ${ }^{3}$, Eric Huttner ${ }^{3}$, Andrzej Kilian ${ }^{3}$ and Kim E Hammond-Kosack*1
}

\begin{abstract}
Address: ${ }^{1}$ Centre for Sustainable Pest and Disease Management, Department of Plant Pathology and Microbiology, Rothamsted Research, Harpenden, Hertfordshire, AL5 2JQ, UK, 2Nickerson-Advanta, Woolpit Business Park, Woolpit, Bury St Edmunds, Suffolk, IP30 0RA, UK, ${ }^{3}$ Diversity Arrays Technology P/L and Triticarte Pty Ltd, 1 Wilf Crane Cr., Yarralumla, Canberra, ACT 2600, Australia and ${ }^{4}$ Centre for Bioenergy Plants Research and Development, Institute of Botany, Chinese Academy of Sciences, Beijing, 100093, PR China

Email: Hai-Chun Jing* - hcjing@ibcas.ac.cn; Carlos Bayon - Carlos.Bayon@bbsrc.ac.uk; Kostya Kanyuka - Kostya.Kanyuka@bbsrc.ac.uk; Simon Berry - Simon.Berry@nickerson.co.uk; Peter Wenzl - Peter@DiversityArrays.com; Eric Huttner - E.huttner@diversityarrays.com; Andrzej Kilian - A.kilian@diversityarrays.com; Kim E Hammond-Kosack* - kim.hammond-kosack@bbsrc.ac.uk

* Corresponding authors
\end{abstract}

Published: 30 September 2009

BMC Genomics 2009, 10:458 doi:10.1 |86/|47|-2/64-10-458
Received: 9 February 2009

Accepted: 30 September 2009

This article is available from: http://www.biomedcentral.com/I47I-2/64/I0/458

(C) 2009 Jing et al; licensee BioMed Central Ltd.

This is an Open Access article distributed under the terms of the Creative Commons Attribution License (http://creativecommons.org/licenses/by/2.0), which permits unrestricted use, distribution, and reproduction in any medium, provided the original work is properly cited.

\begin{abstract}
Background: Triticum monococcum $(2 n=2 x=14)$ is an ancient diploid wheat with many useful traits and is used as a model for wheat gene discovery. DArT (Diversity Arrays Iechnology) employs a hybridisationbased approach to type thousands of genomic loci in parallel. DArT markers were developed for $T$. monococcum to assess genetic diversity, compare relationships with hexaploid genomes, and construct a genetic linkage map integrating DArT and microsatellite markers.

Results: A DArT array, consisting of 2304 hexaploid wheat, 1536 tetraploid wheat, 1536 T. monococcum as well as $1536 \mathrm{~T}$. boeoticum representative genomic clones, was used to fingerprint $16 \mathrm{~T}$. monococcum accessions of diverse geographical origins. In total, 846 polymorphic DArT markers were identified, of which 317 were of $T$. monococcum origin, 246 of hexaploid, 157 of tetraploid, and 126 of T. boeoticum genomes. The fingerprinting data indicated that the geographic origin of $T$. monococcum accessions was partially correlated with their genetic variation. DArT markers could also well distinguish the genetic differences amongst a panel of 23 hexaploid wheat and nine T. monococcum genomes. For the first time, 274 DArT markers were integrated with 82 simple sequence repeat (SSR) and two morphological trait loci in a genetic map spanning $1062.72 \mathrm{cM}$ in $T$. monococcum. Six chromosomes were represented by single linkage groups, and chromosome $4 \mathrm{~A}^{\mathrm{m}}$ was formed by three linkage groups. The DArT and SSR genetic loci tended to form independent clusters along the chromosomes. Segregation distortion was observed for one third of the DArT loci. The Ba (black awn) locus was refined to a $23.2 \mathrm{cM}$ region between the DArT marker locus wPt-2584 and the microsatellite locus Xgwmd33 on IAm; and the $H I$ (hairy leaf) locus to a 4.0 CM region between DArT loci 376589 and 469591 on $5 A^{m}$.

Conclusion: DArT is a rapid and efficient approach to develop many new molecular markers for genetic studies in T. monococcum. The constructed genetic linkage map will facilitate localisation and map-based cloning of genes of interest, comparative mapping as well as genome organisation and evolution studies between this ancient diploid species and other crops.
\end{abstract}




\section{Background}

Triticum monococcum $(2 n=2 x=14)$, generally known as einkorn wheat, is an ancient diploid species domesticated in the Fertile Crescent $~ 10,000$ years ago ([1]. This species dominated human farming activities in the Neolithic period. However, the cultivation area gradually decreased during the Bronze Age due to domestication of tetraploid and hexaploid wheat [2]. In modern times T. monococcum remains cultivated at low scale only in the mountainous areas of several Mediterranean countries. This species has not been bred intensively and therefore retained its genetic diversity [3].

Wild relatives of hexaploid wheat are known to be important sources of traits for wheat genetic improvement. $T$. monococcum $\left(\mathrm{A}^{\mathrm{m}} \mathrm{A}^{\mathrm{m}}\right)$ is closely related to T. urartu $\left(\mathrm{A}^{\mathrm{u}} \mathrm{A}^{\mathrm{u}}\right)$, the donor of the A-genome of hexaploid wheat [4-6]. Recently, T. monococcum has gradually been recognised as an attractive diploid model for exploitation of useful traits, discovery of novel genes and variant alleles, and functional genomics. Many traits have been examined in T. monococcum which can be useful for modern wheat breeding [7-9]. T. monococcum has also been successfully used for gene discovery in a subgenome map-based cloning approach, as exemplified by the cloning of the leaf rust resistance gene $\operatorname{Lr} 10[10,11]$, the vernalisation genes VRN1 and VRN2 [12,13], the domestication locus $Q$ $[14,15]$, and a member of the senescence and nutrient remobilisation controlling NAC gene family [16]. Natural and artificially mutagenised $T$. monococcum populations have been made available and were used to identify and map genes of agronomic importance $[17,18]$. Furthermore, TILLING (Targeting Induced Local Lesions IN Genomes) and VIGS (Virus Induced Gene Silencing) platforms for functional genomics are under development in several laboratories (http://www.wgin.org.uk; http:// www.plantsciences.ucdavis.edu/dubcovsky). Thus, in the foreseeable future T. monococcum is expected to play an important role in wheat genetic and genomic studies.

Globally, thousands of accessions of T. monococcum have been collected and retained in major germplasm stock centres. In order to use T. monococcum resources efficiently in programmes on genetic improvement of hexaploid wheat, it is necessary to assess diversity of this species at the genome level. For this, high-throughput molecular marker technologies are needed. T. monococcum has been shown to possess a high level of polymorphism at DNA marker loci[19]. RFLP (Restriction fragment length polymorphism) and AFLP (Amplified fragment length polymorphism) markers have been developed and used for generating genetic linkage maps and for mutation mapping, map-based cloning, and genome synteny comparisons [4,20-23]. These markers have also been used to resolve the site of the T. monococcum domestication [1].
Microsatellite markers (also called simple sequence repeats or SSRs) have been tested in T. monococcum in comparison with hexaploid wheat and its A-genome donor diploid species $T$. urartu. This information has been used to produce a genetic map integrating RFLPs and SSRs $[24,25]$. However, the aforementioned markers are primarily gel-based and sequence-dependent. The cost per data point, labour-intensive assay procedures and the limitation of polymorphism of the current marker technologies restricts their application to whole-genome scan approaches such as large-scale genotyping of germplasm collections, association mapping, pedigree analysis and QTL (Quantitative Trait Loci) Mapping As You Go [26].

Diversity Arrays Technology (DArT) has been developed as a sequence-independent and micro-array hybridisation-based marker system [27]. DArT generates mediumdensity genome scans by scoring the presence versus absence of DNA fragments in representations of genomic DNA samples. It simultaneously determines hundreds to thousands of polymorphic loci in a single assay $[27,28]$. Since its initial development in rice, DArT has been employed in genetic mapping, genotyping and diversity assessment in barley [28-31], Arabidopsis [32], cassava [33], sorghum [34], hexaploid and durum wheat [35-38], and approximately 30 other plant species (Diversity Arrays Technolgy P/L, unpublished data). DArT has also been used to study pan-genomic evolution in non-model organisms [39] because of its high-throughput and costeffective nature.

We report here the results of a study aimed to (1) develop a T. monococcum diversity array (DArT) for high-throughput genome-wide genotyping, (2) assess the utility of the DArT technology for analysis of genetic diversity in a representative collection of $T$. monococcum accessions, (3) compare the relationships between the $A^{m}$-genome and other Triticum genomes using DArT markers, (4) produce a genetic linkage map for T. monococcum integrating DArT and SSR markers, and (5) refine the genome locations of two morphological trait loci.

\section{Results \\ Array composition}

A total of 1536 DArT clones were developed from a PstI/ TaqI representation generated from a mixture of DNA of two T. monococcum accessions MDR002 and MDR308 [35]. These two accessions were the parents for a large mapping population, which had previously been genotyped with SSR markers and used for mapping several agronomically important traits $[8,9]$. In a parallel project, a substantial number of DArT clones were developed from genomic representations of other Triticum species with different ploidy levels (Triticarte $\mathrm{P} / \mathrm{L}$, unpublished). We combined clones from all projects to assemble a custom- 
designed array containing 1536 clones derived from the two T. monococcum accessions, 2304 clones derived from hexaploid wheats (including the Triticarte Wheat 2.3 array), 1536 clones derived from tetraploid durum wheat (including the Triticarte Durum 2.0 array), and 1536 clones derived from 15 Iranian accessions of T. boeoticum Boiss., which is the wild relative of $T$. monococcum (see Additional file 1; Ali Mehrabi, unpublished data).

\section{Genetic diversity amongst T. monococcum accessions revealed by DArT}

The composite array was used to assess the genetic diversity amongst sixteen T. monococcum accessions listed in Table 1 . They were pre-selected based on their geographical origins, useful traits, available molecular and genetic tools, as well as genetic relationships assessed using SSR fingerprinting [8].

In total, 846 DArT markers were identified as polymorphic amongst the 16 accessions. Polymorphism Information Content (PIC) values for these markers were relatively low, with only $35.5 \%$ of DArTs having PIC val- ues of $0.4-0.5$ and $34.6 \%$ with PIC values $<0.2$ (Table 2). The average mean PIC value was 0.31 . When the quality of the DArT markers (measured as the $\%$ of total variance in hybridisation intensity between the two clusters: present and absent) was analysed against their performance, which is determined through call rate and PIC values, more than half of the polymorphic DArT markers $(n$ $=439$ ) were in the $90-100 \%$ quality category with an average PIC value of 0.34 and call rate of $99.8 \%$, respectively (Table 3 ). The average PIC value decreased with the average quality value. PIC values were $>0.30$ when the marker quality was $>80 \%$. However, PIC values were reduced to $0.24,0.13$ and 0.12 for markers with the quality values of $70-80 \%, 60-70 \%$ and $50-60 \%$, respectively.

This set of polymorphic DArT markers was used to assess the genetic diversity of the 16 T. monococcum accessions. A Jaccard similarity matrix was generated and used to construct a principal coordinate plot deciphering the genetic relationships among the accessions (Figure 1). The first two principal coordinates derived from the scores jointly explained $23.74 \%$ of the total data variance. There was a

Table I: T. monococcum accessions used in this study

\begin{tabular}{|c|c|c|c|c|c|c|}
\hline Accession & Variety & Origin Country & Year of collection & Growth habit & Donors & Resources \\
\hline MDR00I & flavescens & Algeria & - & Spring & $\mathrm{JIC}^{6}$ & Transformable $^{12}$ \\
\hline MDR002 & atriaristatum & Balkans & - & Spring & JIC & $\begin{array}{l}\text { Transformable }{ }^{12} \text {, mapping } \\
\text { population }\end{array}$ \\
\hline MDR024 & hornemannii; flavescens & Chechen & 1904 & Spring & $\mathrm{VIR} \mathrm{R}^{7}$ & \\
\hline MDR037 & macedonicum & Armenia & 1934 & Spring & VIR & \\
\hline MDR040 & vulgare; macedonicum & Bulgaria & 1940 & Spring & VIR & Mapping population \\
\hline MDR043 & vulgare & Greece & 1950 & Spring & VIR & Mapping population \\
\hline MDR044 & hornemannii & Turkey & 1965 & Spring & VIR & Mapping population \\
\hline MDR045 & vulgare & Denmark & 1970 & Spring & VIR & \\
\hline MDR046 & atriaristatum/macedonicum & Romania & 1970 & Spring & VIR & \\
\hline MDR047 & macedonicum; vulgare & Hungary & 1970 & Winter & VIR & \\
\hline MDR049 & pseudohornemannii & Iran & & Winter & VIR & \\
\hline MDR050I & & Italy & & Spring & JIC & EMS mutagenised population ${ }^{13}$ \\
\hline MDR217 & & Turkey & & Spring & USDA $^{8}$ & Mapping population \\
\hline MDR229 & & Spain & & Spring & USDA & Mapping population \\
\hline MDR308² & & Italy & & Spring & UC Davis 9 & $\begin{array}{l}\text { BAC library, genetic map, EST } \\
\text { library, mapping populations }\end{array}$ \\
\hline MDR6503 & & Iran & & & USDA & \\
\hline MDR6524 & & Turkey & & & ACPFG 10 & Mapping populations \\
\hline MDR6575 & & $?$ & & & MPIII & Mapping populations \\
\hline
\end{tabular}

ISelection from a cross between T. monococcum and T. sinskajae (Korzun et al., 1998) [42].

${ }^{2}$ T. monococcum DV92; provided by Jorge Dubcovsky, UC Davies, USA.

${ }^{3}$ T. monococcum PI 355520 from USDA, ARS, USA.

${ }^{4}$ T. monococcum AUSI6273-2; provided by Dr. Yuri Shavrukov, ACPFG, Australia.

${ }^{5}$ T. monococcum LI I8; provided by Benjamin Killian, MPI, Cologne, Germany.

6John Innes Centre, Norwich, United Kingdom.

${ }^{7}$ N. I. Vavilov Institute of Plant Industry, St. Petersburg, Russian Federation.

8 United States Department of Agriculture, Agricultural Research Service, Aberdeen, ID, USA.

YUniversity of California, Davis, CA, USA.

${ }^{10}$ Australian Centre for Plant Functional Genomics, Canberra, Australia.

I'Max Planck Institute, Cologne, Germany.

${ }^{12}$ Huw Jones, Rothamsted Research, Harpenden, UK, personal communication.

${ }^{13}$ Kay Denyer, John Innes Centre, UK, personal communication. 
Table 2: Polymorphism information content (PIC) values for 846 DArT markers developed from $T$. monococcum genome.

\begin{tabular}{lll}
\hline PIC value & Number of DArTs & \% total DArTs \\
\hline $0.5-0.4$ & 300 & 35.5 \\
$0.4-0.3$ & 131 & 15.5 \\
$0.3-0.2$ & 122 & 14.4 \\
$0.2-0.1$ & 161 & 19 \\
$0.1-0.0$ & 132 & 15.6 \\
\hline
\end{tabular}

clear separation for most of the T. monococcum accessions and partial correlations between genetic relationships and geographic origins. The accession MDR650 (PI 355520) of Iranian origin was fairly distantly related to other accessions including most of the accessions of European origin. This accession is unique in its ability to produce fertile $\mathrm{F}_{1}$ hybrids with hexaploid wheat [40]. MDR650 is also a known source of resistance to leaf rust [41] and provides resistance to a range of other wheat pathogens (HCJ and KHK, unpublished). Our previous diversity study using SSR fingerprinting has shown that another Iranian accession MDR049 also formed an independent clade [8]. Furthermore, in the current study MDR308 and MDR043 were clustered close to each other and were distant to MDR002. Amongst the 14 analysed accessions there were two accessions with unusual pedigrees. MDR050 is an inbred line derived from a cross between $T$. monococcum and Triticum sinskajae [42], whereas MDR657 (L118) is a recombinant inbred line generated by several rounds of crosses and backcrosses between Triticum boeoticum and Triticum urartu (B. Kilian, personal communication).

\section{Relationships between the genomes of $\mathrm{T}$. monococcum and related Triticum spp}

As described above, the custom-designed DArT array contained clones developed from the T. monococcum genome and clones derived from the genomes of other Triticum species. This allowed us to assess (1) the degree of genetic similarity/diversity between different $T$. monococcum accessions, and (2) the relationships between the genome of T. monococcum and the A-genomes of other closely related Triticum species. Analysis of the 16 T. monococcum accessions revealed that 317 of the 1536 of DArT markers ( 20\%) developed from T. monococcum accessions MDR002 and MDR308 were polymorphic (Table 4). In this set of T. monococcum accessions 10\% of DArT mark- ers derived from the genomes of hexaploid and tetraploid wheat were polymorphic, whereas only $\sim 8.2 \%$ of DArTs derived from $T$. boeoticum were polymorphic. The latter markers also displayed the lowest PIC values. A similar trend was observed for the polymorphic DArT markers in the $\mathrm{F}_{2}$ mapping population derived from MDR308 $\times$ MDR002 cross (see below). Overall, the DArT markers developed from $T$. monococcum genome were found to be more informative than those developed from the genomes of other related Triticum species.

To test the power of the DArT markers of different origins in resolving the T. monococcum relationships, the 846 polymorphic DArT markers were split according to their genome origins and principal coordinate analyses were carried out using the four subset data. The percentages of total data variance explained by the first two coordinates were $27.75 \%$ in hexaploid wheat, $23.96 \%$ in tetraploid wheat, $35.26 \%$ in genomes of $T$. boeoticum, and $35.77 \%$ in T. monococcum, respectively (Figure 2). These principal coordinate similarity matrices had a correlation coefficient between 0.73-0.94 in describing the relationships among these T. monococcum accessions (Table 5). The Mantel test [43] indicated that the matrices are highly significantly associated (all the $p=0.000$, less than 0.001 ).

To further analyse the relationships of the genomes of $T$. monococcum and those of hexaploid wheat, we simultaneously hybridised the genomes of nine T. monococcum accessions and 23 hexaploid wheat varieties of European, American and Chinese origins to a customised Triticarte DArT array (see Additional file 2). The ploidy levels of the genomes did influence the scoring and hence the raw data was analysed to identify DArT markers which were not affected by this genome context-dependent scoring. As shown in Table 6, 1036 DArT markers were reliably scored, of which 696 markers were polymorphic in hexaploid wheat genomes but were commonly present or absent in T. monococcum genomes; whilst 238 markers were polymorphic in $T$. monococcum genomes but were monomorphic in hexaploid genomes. However, there were 102 DArT markers which were polymorphic in the genomes of both ploidy. The principal coordinate plot constructed using these DArT markers showed that 38\% of the variation was explained by the two-dimensional analysis (Figure 3). The plot showed a good separation of

Table 3: The relationship between the quality and the performance of the 846 DArT markers developed from T. monococcum genome.

\begin{tabular}{lllllll}
\hline Quality (\%) & $\mathbf{1 0 0 - 9 0}$ & $\mathbf{9 0 - 8 0}$ & $\mathbf{8 0 - 7 0}$ & $\mathbf{7 0 - 6 0}$ & $\mathbf{6 0 - 5 0}$ & Grand mean \\
\hline Number of markers & 439 & 237 & 112 & 43 & 15 & 846 \\
Call rate & $99.8 \pm 1.2$ & $98.8 \pm 2.8$ & $97.9 \pm 3.7$ & $99.0 \pm 2.5$ & $99.3 \pm 2.0$ & $99.2 \pm 2.4$ \\
PIC & $0.34 \pm 0.14$ & $0.32 \pm 0.14$ & $0.24 \pm 0.14$ & $0.13 \pm 0.03$ & $0.12 \pm 0.02$ & $0.31 \pm 0.15$
\end{tabular}




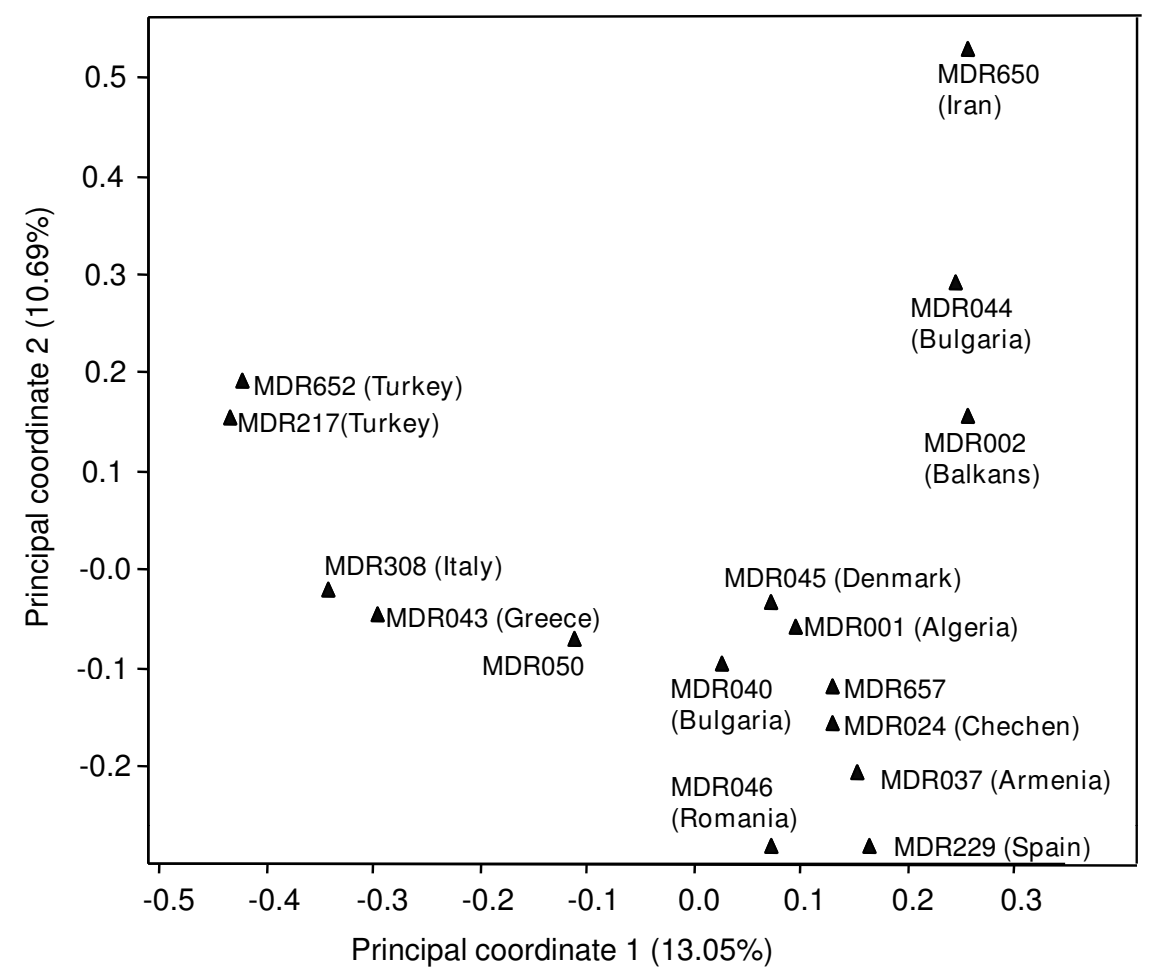

Figure I

Principal coordinate analysis of 16 T. monococcum accessions based on 846 DArT markers. The accession codes and their sites of collection are inserted in the figure. The diagram shows the position of each accession in the space spanned by the first two coordinates of a relative Jaccard similarity matrix.

the genomes with different ploidy levels and the genomes within each ploidy level.

\section{Genetic mapping of DArT and microsatellite (SSR) loci}

To confirm that DArT markers were inherited in a Mendelian manner, we constructed a linkage map for a cross between T. monococcum accessions MDR308 and MDR002 [8]. Hybridising the array with a total of $94 \mathrm{~F}_{2}$ progeny from this cross as well as the two parental accessions identified 300 polymorphic DArT markers: 133, 71, 61 and 35 were derived from genomes of T. monococcum, hexaploid wheat, tetraploid wheat, and $T$. boeoticum, respectively (Table 4). The same T. monococcum mapping population was also genotyped using microsatellite markers mapped to the A sub-genome of hexaploid wheat [44]. Out of 274 microsatellite markers analysed, 90 (32.8\%) were polymorphic between the two parental T. monococcum accessions MDR002 and MDR308. Rates of polymorphism for different types of microsatellite markers were as follows: WMC - 41.9\% (36 polymorphic markers out of 86 examined), CFA and CFD - 39.3\% (11 out of 28), BARC markers $-38.2 \%$ (21 out of 55), GDM and WMS - 33.7\% (28 out of 83 ), and DuPw - 13.6\% (3 out of 22). The data for DArT and microsatellite markers were merged for construction of a genetic linkage map for T. monococcum.
Map length and genome coverage

In total, 356 (274 DArTs and 82 SSRs) molecular markers were mapped and formed nine linkage groups (Figure 4). Some DArT and microsatellite markers were removed from the data during the map construction due to a lack of linked anchor markers. The two morphological traits, namely awns colour and leaf hairiness, were found to segregate in a 1:3 ratio in the MDR308 $\times$ MDR002 T. monococcum mapping population. Therefore, these traits are thought to be controlled by single genes $\mathrm{Ba}$ (black awn) and $\mathrm{Hl}$ (hairy leaf) and were also included in the linkage analysis (see below). The linkage map derived from the combined data set spanned $1062.72 \mathrm{cM}$, with an average length of $151.82 \mathrm{cM}$ per chromosome and an average density of one marker per $2.97 \mathrm{cM}$. Each of the seven chromosomes contained both DArT and SSR markers. Six of the linkage groups corresponded to six T. monococcum chromosomes, but the chromosome $4 \mathrm{~A}^{\mathrm{m}}$ was formed by three linkage groups.

\section{Marker distribution amongst chromosomes}

Various numbers of DArT and SSR markers were mapped to individual chromosome linkage groups (Table 7). Chromosome $4 \mathrm{~A}^{\mathrm{m}}$ contained the lowest numbers $(n=$ 34 ) of the molecular markers, while the highest numbers 
Table 4: Number and feature of polymorphic DArT markers identified in this study

\begin{tabular}{llllc}
\hline & Hexaploid wheat & Tertraploid wheat & T. boeoticum & T. monococcum \\
\hline Total DArT & 2304 & 1536 & 1536 & 1536 \\
Polymorphic among 16 accessions & & & $126(8.20 \%)$ & $317(20.64 \%)$ \\
Mean quality (\%) & $246(10.68 \%)$ & $157(10.22 \%)$ & $88.7 \pm 8.8$ \\
Mean call rate (\%) & $86.3 \pm 9.6$ & $86.7 \pm 9.3$ & $95.0 \pm 10.6$ & $99.1 \pm 2.6$ \\
Mean PIC & $99.3 \pm 2.1$ & $99.1 \pm 2.1$ & $0.3 \pm 2.1$ & $0.32 \pm 0.14$ \\
Polymorphic between MDR002 and MDR308 & $0.30 \pm 0.14$ & $0.32 \pm 0.15$ & $35(2.28 \%)$ & $133(8.66 \%)$ \\
Mean quality (\%) & $71(3.08 \%)$ & $61(3.97 \%)$ & $82.3 \pm 4.9$ & $85.3 \pm 5.6$ \\
Mean call rate (\%) & $84.1 \pm 6.0$ & $83.3 \pm 4.6$ & $93.1 \pm 2.7$ & $94.6 \pm 3.0$ \\
Mean PIC & $93.8 \pm 3.6$ & $93.5 \pm 2.8$ & $0.43 \pm 0.04$ & $0.40 \pm 0.07$ \\
\hline
\end{tabular}

$(n=68)$ were found on chromosome $7 \mathrm{~A}^{\mathrm{m}}$. KolmogorovSmirnov tests were performed to compare nonparametrically the equality of the distributions of the DArT and SSR markers along individual chromosomes. The results showed that chromosomes $1 \mathrm{~A}^{\mathrm{m}}, 3 \mathrm{~A}^{\mathrm{m}}, 5 \mathrm{~A}^{\mathrm{m}}, 6 \mathrm{~A}^{\mathrm{m}}$ and $7 \mathrm{~A}^{\mathrm{m}}$ had $p$-values smaller than 0.05 but chromosomes $2 \mathrm{~A}^{\mathrm{m}}$ and $4 \mathrm{~A}^{\mathrm{m}}$ had larger $p$-values. These results suggest that DArT and SSR tended to form independent clusters on chromosomes in T. monococcum.

\section{Distribution of DArT markers derived from genomes of different Triticum species}

The mapped 274 polymorphic DArT markers were derived from T. aestivum, T. durum, T. monococcum and T. boeoticum. Figure 5 shows the numbers of the four category DArT markers and SSR markers on the seven chromosomes. Chi-square goodness-of-fit test of associations between origins of DArT markers and T. monococcum linkage groups showed that the distribution of DArT markers arising from different genomes and SSR markers was at random across chromosomes (Pearson $\chi^{2}=27.49$ with 34 d.f., probability level under null hypothesis $p=0.778$ ). However, in some cases, DArT markers of certain origins were either over- or under-numbered. For instance, the related A genome DArT markers were under-represented on chromosomes $3 \mathrm{~A}^{\mathrm{m}}$, but over-represented on $7 \mathrm{~A}^{\mathrm{m}}$.

Fifty-eight of these markers are with known locations in genomes of hexaploid and tetraploid wheat (Triticarte P/
L, unpublished); only 33 are of A-genome origins (Table 8 ), suggesting that B and D genomes of other Triticum species could provide substantial polymorphic information in the $\mathrm{A}^{\mathrm{m}}$ genome of T. monococcum. Each of the seven $T$. monococcum chromosomes carried loci of the DArT markers that were previously mapped to homoeologous chromosomes in the B- or D-genomes of Triticum species (Figure 4). Also, the map positions of some of the Agenome derived DArTs determined in our study disagreed with those obtained in previous studies. For instance, some of the markers thought to map to 4A and 7A in hexaploid and tetraploid wheat were mapped to the chromosome $2 \mathrm{~A}^{\mathrm{m}}$ in $\mathrm{T}$. monococcum, whereas some other DArTs thought to map to $7 \mathrm{~A}$ in hexaploid and tetraploid wheat were mapped to either $4 \mathrm{~A}^{\mathrm{m}}$ or $5 \mathrm{~A}^{\mathrm{m}}$ in our study (Table 8 , and Figure 4).

\section{Segregation distortion}

In total, 156 markers were significantly distorted from the expected Mendelian segregation ratios $(P<0.05)$. These were more or less equally distributed across the genome (Figure 6). The chromosomes $1 \mathrm{~A}^{\mathrm{m}}, 2 \mathrm{~A}^{\mathrm{m}}, 3 \mathrm{~A}^{\mathrm{m}}, 4 \mathrm{~A}^{\mathrm{m}}, 5 \mathrm{~A}^{\mathrm{m}}$, $6 \mathrm{~A}^{\mathrm{m}}$ and $7 \mathrm{~A}^{\mathrm{m}}$ contained $37.8 \%(17 / 37), 43.5 \%(30 / 69)$, $46.2 \%$ (24/52), 38.2\% (13/34), 30.4\% (17/56), 30.9\% (13/42) and $14.7 \%(10 / 68)$ of markers displaying strong allelic frequency distortion, respectively. For some markers the segregation distortion was in favour of alleles originating from the male parent MDR002, whereas for other markers the segregation distortion was in favour of alleles

Table 5: Correlation between pairs of similarity matrices describing the relationships of $T$. monococcum accessions generated by using DArT markers from different origins.

\begin{tabular}{llllll}
\hline & Whole DArT set & Hexaploid & Tetraploid & T. monococcum & T. boeoticum \\
\hline Whole DArT set & $*$ & & & & \\
Hexaploid & $0.92(0.000)$ & $*$ & & & \\
Tetraploid & $0.87(0.000)$ & $0.76(0.000)$ & $*$ & $0.75(0.000)$ & $*$ \\
T. monococcum & $0.94(0.000)$ & $0.79(0.000)$ & $0.73(0.000)$ & $0.73(0.000)$ & $*$ \\
T. boeoticum & $0.86(0.000)$ & $0.75(0.000)$ & & \\
\hline
\end{tabular}

Numbers between parentheses are the $p$-values for testing the null hypothesis of no association by Mantel test. 

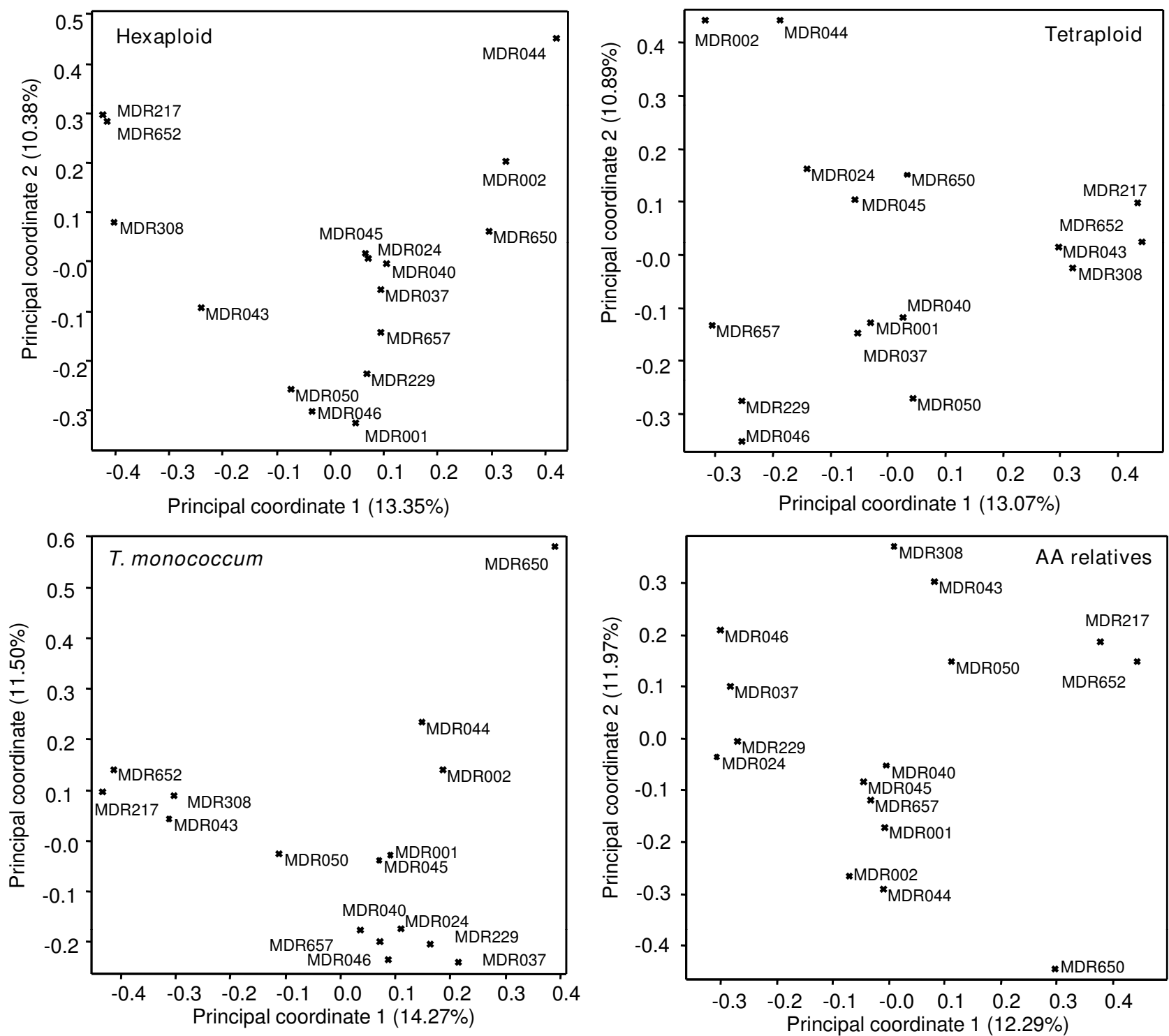

Figure 2

Principal coordinate analysis of 16 T. monococcum accessions based on the DArT markers from T. monococcum as well as from diploid, tetraploid and hexaploid Triticum species. The diagrams show the positions of individual accessions in the space spanned by the first two coordinates of a relative Jaccard similarity matrix. The relationships depicted by the four matrices are highly associated as indicated by the Mantel test (see text for details).

originating from the female parent MDR308 (Figure 4). The predominant alleles on the chromosomes $1 \mathrm{~A}^{\mathrm{m}}$ and $2 \mathrm{~A}^{\mathrm{m}}$ were from MDR308, whereas those on $4 \mathrm{~A}^{\mathrm{m}}$ were from MDR308. Chromosomes $3 \mathrm{~A}^{\mathrm{m}}, 4 \mathrm{~A}^{\mathrm{m}}, 5 \mathrm{~A}^{\mathrm{m}}, 6 \mathrm{~A}^{\mathrm{m}}$ and $7 A^{\text {omum }}$ contained marker alleles originating from either male of female parents, displaying frequencies skewed from their Mendelian expectations.

\section{Fine-mapping of morphological trait loci}

In T. monococcum, black awns and hairy leaves are two morphological traits known to be controlled by single dominant genes $B a$ and $H l$, respectively. Our previous genetic study revealed a linkage between $B a$ and the SSR locus Xwmc336 on $1 \mathrm{~A}^{\mathrm{m}}$, and between $\mathrm{Hl}$ and the SSR locus $X c f d 39$ on $5 \mathrm{~A}^{\mathrm{m}}[8]$. These two traits segregated in MDR002 $\times$ MDR308 $\mathrm{F}_{2}$ mapping population as single independent loci and therefore it was possible to refine the positions of $\mathrm{Ba}$ and $\mathrm{Hl}$ in T. monococcum genome. Previous estimations showed that the genetic distance was $21.5 \mathrm{cM}$ between $\mathrm{Ba}$ and $X w m c 336$, and $17.4 \mathrm{cM}$ between $\mathrm{Hl}$ and $\mathrm{Xcfd39}$. Linkage analysis combining SSR and DArT markers confirmed that $\mathrm{Ba}$ was located at $80.09 \mathrm{cM}$ on $1 \mathrm{~A}^{\mathrm{m}}$ between the DArT 
Table 6: Comparison of DArT markers hybridised to T. monococcum and hexaploid wheat genomes

\begin{tabular}{|c|c|c|c|c|c|c|c|c|}
\hline & Numbers & Quality & Call Rate & PIC & $\begin{array}{l}\text { Scored in } T . \\
\text { monococcum }\end{array}$ & $\begin{array}{l}\text { Scored in } \\
\text { hexaploid } \\
\text { wheat }\end{array}$ & $\begin{array}{l}\text { Score in } T . \\
\text { monococcum }\end{array}$ & $\begin{array}{l}\text { Score in } \\
\text { hexaploid } \\
\text { wheat }\end{array}$ \\
\hline $\begin{array}{l}\text { Polymorphic in } \\
\text { both ploidy }\end{array}$ & 102 & $80.5 \pm 6.9$ & $96.6 \pm 4.1$ & $0.38 \pm 0.1$ & Yes & Yes & $0.51 \pm 0.32$ & $0.45 \pm 0.33$ \\
\hline $\begin{array}{l}\text { Present in diploid, } \\
\text { polymorphic in } \\
\text { hexaploid }\end{array}$ & 358 & $80.3 \pm 7.4$ & $97.9 \pm 2.7$ & $0.41 \pm 0.11$ & No & Yes & $1.00 \pm 0.00$ & $0.44 \pm 0.27$ \\
\hline $\begin{array}{l}\text { Absent in diploid, } \\
\text { polymorphic in } \\
\text { hexaploid }\end{array}$ & 338 & $82.0 \pm 7.0$ & $97.9 \pm 2.5$ & $0.44 \pm 0.08$ & No & Yes & $0.00 \pm 0.00$ & $0.67 \pm 0.24$ \\
\hline $\begin{array}{l}\text { Present in } \\
\text { hexaploid, } \\
\text { polymorphic in } \\
\text { diploid }\end{array}$ & 42 & $78.3 \pm 11.0$ & $96.9 \pm 5.7$ & $0.27 \pm 0.12$ & Yes & No & $0.41 \pm 0.29$ & $1.00 \pm 0.00$ \\
\hline $\begin{array}{l}\text { Absent in } \\
\text { hexaploid, } \\
\text { polymorphic in } \\
\text { diploid }\end{array}$ & 196 & $82.7 \pm 10.0$ & $96.9 \pm 5.7$ & $0.26 \pm 0.11$ & Yes & No & $0.57 \pm 0.28$ & $0.00 \pm 0.00$ \\
\hline
\end{tabular}

marker locus $w P t-2584$ at $60.59 \mathrm{cM}$ and the SSR locus $\mathrm{Xgwmd33}$ at $83.76 \mathrm{cM}$, and $\mathrm{Hl}$ was located at $136.16 \mathrm{cM}$ on $5 \mathrm{~A}^{\mathrm{m}}$ between the DArT marker loci 376589 at 134.84 $\mathrm{cM}$ and 469591 at $138.77 \mathrm{cM}$.

\section{Discussion}

The availability of a high density genetic linkage map for a species is essential for identifying QTLs of interest, isolation of genes by map-based cloning, comparative mapping, and genome organisation and evolution studies [45]. We have developed polymorphic DArT markers from genome representations of two T. monococcum accessions, 15 T. boeoticum, and hexaploid and tetraploid Triticum species. The genetic linkage map of $T$. monococcum constructed in this study is the first map integrating DArT and SSR markers.

\section{Determining genetic relationships between $\mathbf{T}$. monococcum accessions and with hexaploid wheat varieties using DArT marker fingerprinting}

DArT markers are typically developed from a representation which is generated from a pool of DNA samples from a number of accessions, cultivars or breeding lines which as a group cover the genetic diversity within a species or a group of closely related species [27]. In the current study, DArT markers were initially generated from genomic representations of two $T$. monococcum accessions, parents of an $\mathrm{F}_{2}$ mapping population. In addition, this study took advantage of the existence of a large number of DArT markers previously developed from hexaploid, tetraploid and other diploid Triticum species.

The inclusion of DArT clones from various genomes meant the average PIC value of the data set $(0.31)$ was lower than in comparable studies. For example, for barley, sorghum and cassava the values obtained were $0.38,0.41$ and 0.42 , respectively $[28,33,34]$. However, the data provided useful information for comparison of Triticum genomes of different ploidy levels. In the genetic diversity assessment of $16 \mathrm{~T}$. monococcum accessions, 20.6\% (317 out of 1536) of the DArT markers developed from the two T. monococcum accessions were polymorphic. DArT markers developed from genomes of other Triticum species also displayed good polymorphism frequencies (10.68\%, $10.22 \%$ and $8.2 \%$ for markers developed from hexaploid, tetraploid and diploid species, respectively) in T. monococcum. In hexaploid wheat, $15.3 \%$ (788 out of 5137) of DArT markers were found to be polymorphic when assessing the genetic diversity of 13 Australian cultivars [35]. Similar studies in durum wheat and barley revealed only $9.6 \%$ and $10.4 \%$ of polymorphic DArTs, respectively $[28,36]$. Thus, the group of $16 \mathrm{~T}$. monococcum accession genotyped in this study appeared to be more genetically diverse than the bread and durum wheat collections assayed in those studies. Furthermore, most of the DArT markers whose genome locations have been determined in previous studies were located on homoeologous chromosomes of T. monococcum. Thus, DArT markers from related genomes were also useful in probing genetic diversity in T. monococcum. The custom-designed DArT array developed here can be used in studies focusing on comparison of the T. monococcum genome with genomes of other Triticum species.

Principal coordinate analysis of the $16 \mathrm{~T}$. monococcum accession revealed that the site of collection is only partially correlated with genetic diversity. Most accessions used in this study have been genotyped with SSR markers 


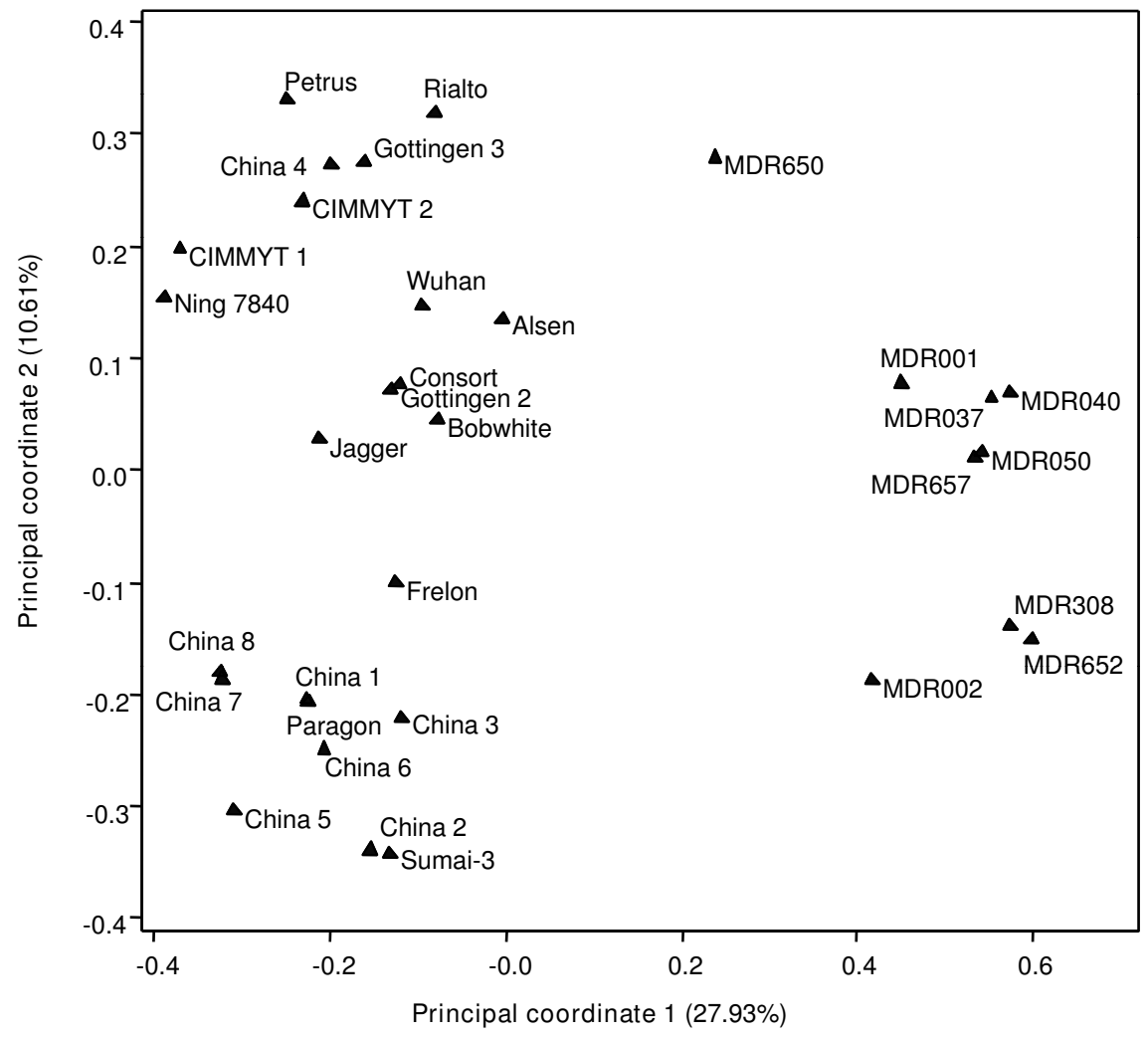

Figure 3

Principal coordinate analysis of nine T. monococcum accessions and 23 T. aestivum varieties based on I02 DArT markers. The diagram shows the position of each accession/variety in the space spanned by the first two coordinates of a relative Jaccard similarity matrix.

in a previous study, and a similar pattern had been observed [8]. Thus, DArT fingerprints are as useful for resolving the genetic relationships in $T$. monococcum as non-DArT based markers. One of the accessions, MDR650 (PI 355520) was found to be genetically distantly related to other T. monococcum accessions, which raised a question whether it is a true T. monococcum. However, MDR650 (PI 355520) possesses the three major traits of the domesticated einkorn wheat: larger and plumper seeds, a tough rachis preventing spikelets falling apart at maturity, and relatively easy threshing. These traits are absent in the wild species T. boeoticum. We have crossed MDR650 (PI 355520) with many other T. monococcum accessions and discovered that the crossability could reach $100 \%$ (data not shown). Furthermore, MDR650 (PI 355520) did not cluster with hexaploid wheat and was closer to the T. monococcum cluster. Thus, we still consider MDR650 (PI 355520) an accession of T. monococcum.

The relationships between the $\mathrm{A}^{\mathrm{m}}$-genome of T. monococcum and those of hexaploid wheat T. aestivum and its subgenome donor, T. urartu have been studied in different context. For instance, chromosome pairing and recombination were studied between homoeologous chromosomes $1 \mathrm{~A}$ and $1 \mathrm{~A}^{\mathrm{m}}, 3 \mathrm{~A}$ and $3 \mathrm{~A}^{\mathrm{m}}$ as well as $5 \mathrm{~A}$ and $5 \mathrm{~A}^{\mathrm{m}}$ and were shown to be collinear and differentiated at sub-structural level $[20,46]$. Good micro-colinearity/colinearity at particular genetic loci has also been reported $[47,48]$. Other studies as well as the present one demonstrate that many A-genome molecular markers could also be used for genetic studies in T. monococcum [24,25]. However, their genome-wide use was not previously reported. The use of DArT markers allowed us to assess the relationships in a new perspective. We showed here that most of the DArT markers which are polymorphic in $T$. monococcum were either conserved or absent in hexaploid genomes, and vice vers $a$, indicative of divergence of the $\mathrm{A}^{\mathrm{m}}$-genome from the A-genome [25]. On the other hand, many DArT markers originated from B- and D-genomes of hexaploid wheat could hybridise to the T. monococcum genomes and provide the polymorphism information in $T$. monococcum. Thus, at the homoeologous genomes level, there is a complex relationship between T. monococcum and hexaploid wheat. 

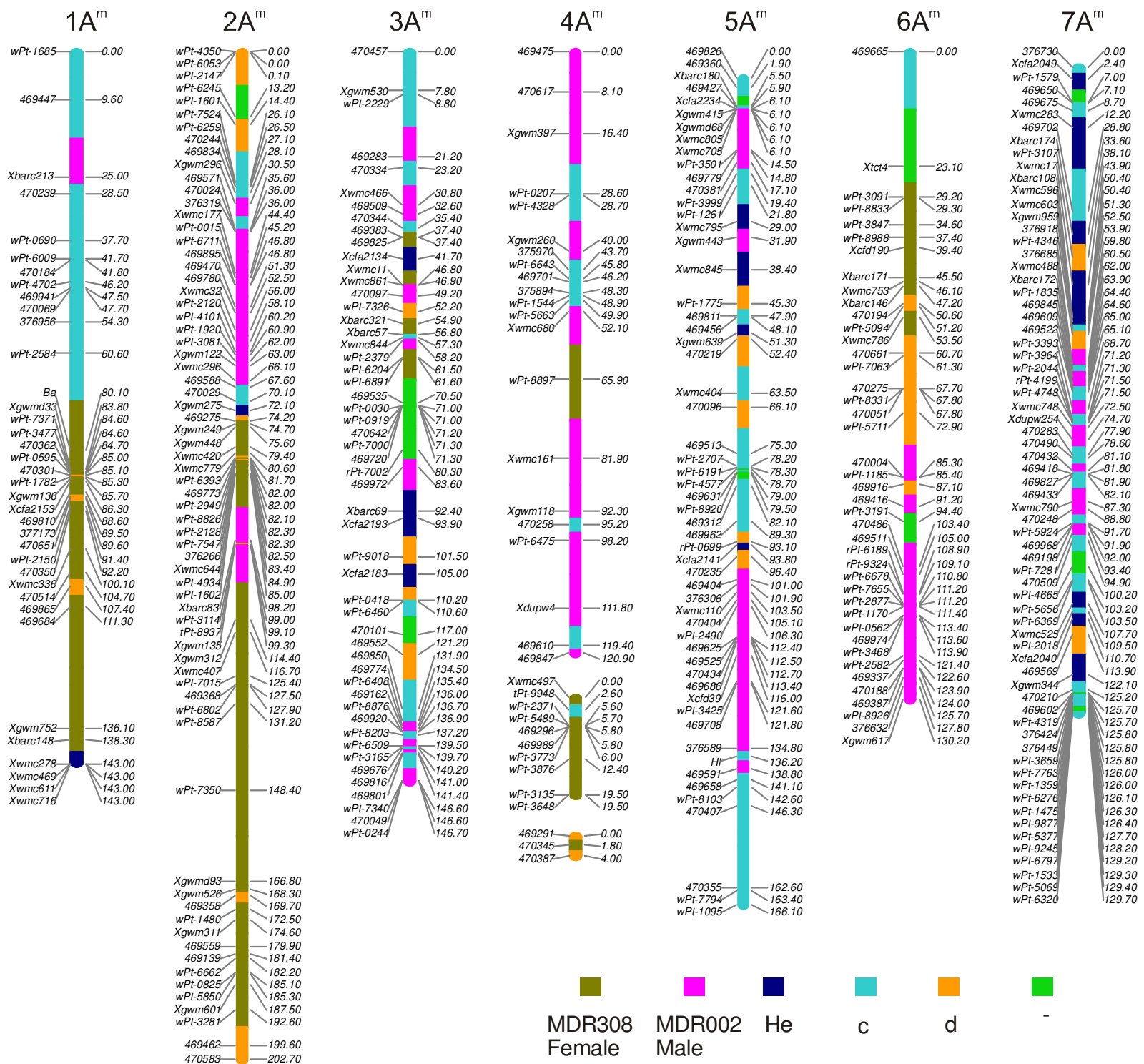

\section{Figure 4}

An integrated DArT and SSR genetic linkage map of T. monococcum. The vertical bars represent the chromosomes of T. monococcum. The codes on the left are the DArT and SSR marker loci, with corresponding map locations in accumulative genetic distance (cM; Kosambi) on the right. The discrete segments of the vertical chromosomal bars are colour-coded according to the allele colour in the figure legends. He stands for alleles heterozygous for female (MDR308) and male (MDR002) alleles, $\mathbf{c}$ for the female (MDR308) alleles in homozygous or heterozygous forms, $\mathbf{d}$ for male (MDR002) alleles in homozygous or heterozygous forms, and - for unknown alleles, respectively.

\section{T. monococcum genetic linkage maps}

A T. monococcum genetic map has been previously constructed using MDR308 (DV92) as one of parental accessions by Dubcovsky et al (1996) [21]. This map contains 335 markers, including RFLPs, isozymes, seed storage proteins, rRNA, and various morphological loci. The total length of this map is $1071.6 \mathrm{cM}$, the average chromosome length is $153.1 \mathrm{cM}$, and the average marker density is one marker per 3.2 cM. More recently, Singh et al (2007) [24] used a T. boeoticum $\times$ T. monococcum RIL population to construct another genetic linkage map integrating 177 SSR and RFLP markers, and two morphological trait loci. The total length of this map is $1262 \mathrm{cM}$, the average chromosome length is $180.3 \mathrm{cM}$, and the average marker density is one marker per $7.05 \mathrm{cM}$. In comparison, our current genetic map derived from linkage analysis of an $\mathrm{F}_{2}$ popu- 
Table 7: Features of a genetic linkage map for T. monococcum integrating DArT and SSR markers

\begin{tabular}{|c|c|c|c|c|c|c|c|c|}
\hline & $\mathbf{I A}^{\mathrm{m}}$ & $2 A^{m}$ & $3 A^{m}$ & $4 A^{m}$ & $5 A^{m}$ & 6Am & 7Am & Total \\
\hline Total markers & 37 & 69 & 52 & 34 & 56 & 42 & 68 & 358 \\
\hline DArT & 25 & 50 & 41 & 27 & 42 & 35 & 54 & 274 \\
\hline SSR & 11 & 19 & 11 & 7 & 13 & 7 & 14 & 82 \\
\hline Morphological trait locus & $\mathrm{I}(\mathrm{Ba})$ & & & & $\mathrm{I}(H I)$ & & & 2 \\
\hline Kolmogorov-Smirnov test & $9.20(0.011)$ & $3.78(0.151)$ & $8.11(0.017)$ & $1.90(0.386)$ & $10.50(0.005)$ & $10.08(0.006)$ & $10.00(0.007)$ & \\
\hline Length (cM) & 143.02 & 202.69 & 146.69 & 144.4 & 166.06 & 130.19 & 129.67 & \\
\hline Density (cM/marker) & 3.87 & 2.94 & 2.82 & 4.24 & 3.01 & 3.1 & 1.96 & 2.97 \\
\hline
\end{tabular}

lation from a cross between MDR308 and MDR002 integrates 274 DArT markers, 82 SSR markers and two morphological trait loci. This map spans over $1062.7 \mathrm{cM}$, with six chromosomes represented by single linkage groups and chromosome $4 \mathrm{~A}^{\mathrm{m}}$ by three groups of linked markers. The average chromosome length is $151.8 \mathrm{cM}$, and the average marker density in the genome is one marker per $2.97 \mathrm{cM}$. Observed differences in lengths and marker densities for the three T. monococcum linkage maps may well be related to differences in the mapping populations, the types and error-rates of the genetic marker systems used, and/or the algorithms and mapping functions used to compute genetic distances. For example, Singh et al (2007) [24] used the Haldane's mapping function, whereas the Kosambi's mapping function was used in other cases.

The current genetic linkage is also very similar in length and in marker densities to the A-genome maps of hexaploid wheat constructed using the Kosambi's map function. In one case, 369 SSR markers were mapped onto a $944 \mathrm{cM}$ A-genome with the marker density of one marker per $2.56 \mathrm{cM}$ [44]. In another study, 464 SSR markers were mapped onto a $1231 \mathrm{cM}$ A-genome with the marker density of one marker per $2.65 \mathrm{cM}$ [49]. Recently DArT markers have also been developed and integrated with conventional markers i.e. SSRs, RFLPs and AFLPs in hexaploid wheat [35] and tetraploid wheat [36].

\section{Genome organisation and segregation distortion}

The $\mathrm{A}^{\mathrm{m}}$-genome of T. monococcum is closely related to the $\mathrm{A}^{\mathrm{u}}$-genome of T. urartu and to the A-genome of the hexaploid wheat [4-6]. This is reflected by the high transferability of SSR markers from hexaploid wheat to $T$. monococcum and the overall good colinearity of SSR arrangement along the chromosomes $[8,24]$. Gaps are frequently observed in hexaploid wheat genetic linkage maps making use of SSR, RFLP and AFLP markers [49-52]. Similarly, Singh et al (2007) [24] observed four large gaps on linkage maps of chromosomes $2 \mathrm{~A}^{\mathrm{m}}, 4 \mathrm{~A}^{\mathrm{m}}$ and $7 \mathrm{~A}^{\mathrm{m}}$ in $T$. monococcum. In contrast, in our current linkage map for $T$. monococcum there was only two gaps on chromosome $4 \mathrm{~A}^{\mathrm{m}}$. This suggests that DArT markers can be used to fill the gaps and help generate higher resolution genetic linkage maps.

Strong segregation distortion was observed during construction of our current genetic linkage map for T. monococcum. Over one third of the marker loci across the seven chromosomes displayed allele frequencies skewed from their Mendelian expectations. This was observed for both DArT and SSR markers, with preferences for both parental alleles. Segregation distortion has also been observed by Dubcovsky et al (1996) [21] and Singh et al (2007) [24] during construction of einkorn wheat genetic linkage maps, regardless of the type of populations used. In one study (Dubcovsky et al 1996) [21] 15\% of the marker loci displayed segregation distortion and were clustered on chromosomes $1 \mathrm{~A}^{\mathrm{m}}$ and $7 \mathrm{~A}^{\mathrm{m}}$, while in other study (Singh et al 2007) [24] two major distorted regions were detected on chromosome $2 \mathrm{~A}^{\mathrm{m}}$. Strong segregation distortion has also been noted during the construction of durum wheat and bread wheat linkage maps integrating SSR and DArT markers [36].

\section{Utility of DArT markers and the genetic linkage map in $\mathrm{T}$. monococcum}

The two parental T. monococcum lines, MDR308 and MDR002, used for developing the $\mathrm{F}_{2}$ mapping population had a number of contrasting traits including awn colour, leaf pubescence, grain hardness, salt tolerance, as well as resistance to the fungus Mycosphaerella graminicola and to soil-borne cereal mosaic viruses $[8,9,53]$. We demonstrated here that the constructed genetic linkage map helped refine the chromosome regions spanning the $B a$ and $\mathrm{Hl}$ trait loci. Also, this map was recently used to refine the TmStb1 locus conferring resistance to M. graminicola isolate IPO323 on chromosome $7 \mathrm{~A}^{\mathrm{m}}$, and to identify and map new QTLs conferring salt tolerance (HCJ and KHK, unpublished). 


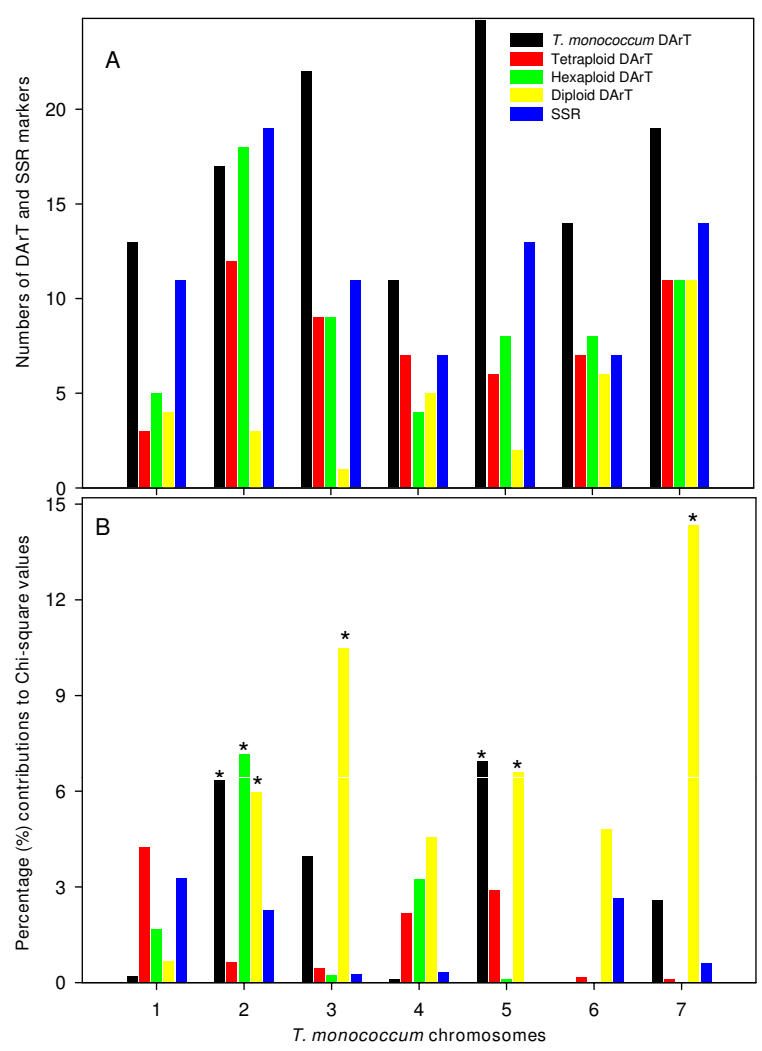

Figure 5

Chromosome distribution (A) of DArT markers developed from genomes of different Triticum species and SSR markers across the seven chromosomes of T. monococcum and the percentage (\%) contributions (B) of the individual marker categories to the overall Chi-square values (Person $\chi^{\mathbf{2}}=\mathbf{2 7 . 4 9}$ at 34 d. f.; $\mathbf{p}=$ $\mathbf{0 . 7 7 8 )}$. The asterisks indicate over- or under-representations of the numbers of the particular DArT and SSR markers on the chromosomes.

MDR308 (also known as DV92), one of the parental lines of the $\mathrm{F}_{2}$ mapping population used in this study, has previously been used for developing a range of molecular tools including a genetic linkage map integrating RFLPs, AFLPs and seed storage proteins [54], a BAC library [55], and several populations of chemically- and radiationinduced mutants http://www.wgin.org.uk. The availability of DArT marker information for MDR308 (DV92) further increases the utility of this accession.

In the near future it should be possible to link various available genetic linkage maps of $T$. monococcum thereby creating a frame work consensus map for wider applications in molecular genetics and genomics studies.

\section{Conclusion}

DArT is a rapid and efficient approach to develop many new molecular markers for genetic studies in T. monococ- cum. The constructed genetic linkage map will facilitate localisation and map-based cloning of genes of interest, comparative mapping as well as genome organisation and evolution studies between this ancient diploid species and other crops.

\section{Methods \\ Plant material}

This study used 16 T. monococcum accessions and an $\mathrm{F}_{2}$ population of 98 individuals derived from a cross between accessions MDR002 and MDR308 [8]. The detailed information about these accessions is also listed in Table 1. In addition, 23 hexaploid wheat varieties collected from UK, continental Europe, China and America, or developed at CIMMYT, Mexico were used for genetic diversity compassion. The information about these hexaploid wheat varieties is provided in Additional file 2.

\section{DArT procedure}

The DNA was extracted from leaves of 2-week-old einkorn wheat seedlings using the DNeasy Plant Mini Kit (QIAGEN) according to manufacturer's instructions. A set of 1536 new DArT clones were generated from a PstI/TaqI representation of the MDR002 and MDR308 accessions as described previously $[28,36]$. The new clones were printed together with 2304 polymorphism-enriched clones from hexaploid wheat, 1536 from tetraploid wheat, and 1536 from a group of 15 Iranian accessions of diploid T. boeoticum (see Additional file 1). The resulting composite array was then used to genotype the T. monococcum samples using the standard DArT protocol $[28,36]$.

\section{Microsatellite assay}

A total of 279 SSR markers mapped to the A-genome of hexaploid wheat were tested for polymorphism between the T. monococcum accessions MDR002 and MDR308. These SSRs originated from 5 groups: 57 BARC markers from the Beltsville Agricultural Research Centre, USA [56,57], 29 CFA and CFD markers from INRA ClermontFerrand, France $[52,58,59], 24$ DuPw markers from DuPont company ([60] et al. 2002, DuPont, unpublished; Dreisigacker et al. 2005), 85 GDM and WMS markers from IPK Gatersleben, Germany [61,62], and 89 WMC markers from the Wheat Microsatellite Consortium [63]. For each SSR primer pair, the 5'-end of the forward primer was labelled with infra-red dye (IRD700 or IRD800, LICOR Biosciences UK Ltd). The PCR were carried out using the PCR Master Mix (Promega) in a 10- $\mu$ l reaction volume containing $1 \times$ PCR Master Mix buffer, $0.1 \mu \mathrm{M}$ forward and reverse primers, and 20-30 ng plant DNA. Amplifications were carried out in 96-well microtiter plates using a Gstorm Thermal Cycler (GS4/GS4s, Gene Technologies, Essex, England). The programmes were $2 \mathrm{~min}$ at $94^{\circ} \mathrm{C}$, followed by $30-35$ cycles of $30 \mathrm{~s}$ at $94^{\circ} \mathrm{C}, 30 \mathrm{~s}$ annealing at $50-60^{\circ} \mathrm{C}$ (depending on the primer pairs), and $1 \mathrm{~min}$ at $72^{\circ} \mathrm{C}$, and a final extension of $5 \mathrm{~min}$ at $72^{\circ} \mathrm{C}$. The final 
Table 8: The distribution of DArT markers originated from genomes of various Triticum species across the seven chromosomes of $T$. monococcum.

\begin{tabular}{|c|c|c|c|c|c|}
\hline Marker Name & $A^{m}$ map position & Am Chromosome & Original chromosome & Source & Clone ID \\
\hline wPt-I685 & 0 & $I A^{m}$ & ID & A-Genome & 375942 \\
\hline wPt-737I & 84.63 & $\mathrm{IA}^{\mathrm{m}}$ & IB & Durum wheat & 379045 \\
\hline wPt-3477 & 84.65 & $\mathrm{IA}^{\mathrm{m}}$ & IB & Bread wheat & I I9840 \\
\hline wPt-0595 & 85.02 & $\mathrm{IA}^{\mathrm{m}}$ & $|A| I B$ & Durum wheat & 346277 \\
\hline wPt-I 782 & 85.26 & $\mathrm{IA}^{\mathrm{m}}$ & $|A| I B$ & A-Genome & 376064 \\
\hline$w P t-2150$ & 91.4 & $\mathrm{IA}^{\mathrm{m}}$ & $\mathrm{IA} \mid 2 \mathrm{~B}$ & Bread wheat & 119519 \\
\hline wPt-6053 & 0.05 & $2 A^{m}$ & $2 B$ & Bread wheat & 120879 \\
\hline wPt-1601 & 14.37 & $2 A^{m}$ & $7 \mathrm{~A}$ & Durum wheat & 381522 \\
\hline wPt-7524 & 26.15 & $2 A^{m}$ & $4 \mathrm{~A}$ & Bread wheat & 116494 \\
\hline wPt-1920 & 60.94 & $2 A^{m}$ & $2 B$ & Durum wheat & 408383 \\
\hline wPt-3 I I4 & 98.95 & $2 A^{m}$ & $2 \mathrm{~A}$ & Bread wheat & II 5722 \\
\hline tPt-8937 & 99.09 & $2 A^{m}$ & $2 \mathrm{~A}$ & Durum wheat & 348413 \\
\hline wPt-70I5 & $|25.4|$ & $2 A^{m}$ & $3 B$ & Bread wheat & 116612 \\
\hline wPt-6802 & 127.86 & $2 \mathrm{~A}^{\mathrm{m}}$ & $3 B$ & Bread wheat & 119652 \\
\hline wPt-7350 & 148.43 & $2 A^{m}$ & $2 B$ & Bread wheat & 116096 \\
\hline wPt- 1480 & 172.52 & $2 \mathrm{~A}^{\mathrm{m}}$ & $2 \mathrm{~A}$ & Bread wheat & 116703 \\
\hline wPt-6662 & 182.22 & $2 A^{m}$ & $2 \mathrm{~A}$ & Bread wheat & 120517 \\
\hline wPt-328I & 192.61 & $2 A^{m}$ & $2 \mathrm{~A}$ & Bread wheat & 115316 \\
\hline wPt-7326 & 52.25 & $3 \mathrm{~A}^{\mathrm{m}}$ & IA & Durum wheat & 408336 \\
\hline wPt-2379 & 58.15 & $3 A^{m}$ & $4 D$ & Bread wheat & || $632 \mid$ \\
\hline wPt-6204 & 61.54 & $3 A^{m}$ & $3 \mathrm{~A}$ & Bread wheat & 120579 \\
\hline wPt-689I & 61.56 & $3 A^{m}$ & $3 \mathrm{~A}$ & Bread wheat & 120585 \\
\hline$w P t-6460$ & 110.58 & $3 A^{m}$ & $7 A$ & Bread wheat & 120067 \\
\hline wPt-8876 & $|36.7|$ & $3 \mathrm{~A}^{\mathrm{m}}$ & $3 \mathrm{~A}$ & Bread wheat & 121186 \\
\hline wPt-6509 & 139.48 & $3 A^{m}$ & $3 D$ & Durum wheat & 345122 \\
\hline wPt-3 I 65 & 139.7 & $3 A^{m}$ & $3 D$ & Bread wheat & 116398 \\
\hline wPt-7340 & 146.65 & $3 \mathrm{~A}^{\mathrm{m}}$ & $3 \mathrm{~A} \mid 3 \mathrm{~B}$ & Durum wheat & 377884 \\
\hline wPt-0244 & 146.69 & $3 A^{m}$ & $3 A \mid 3 B$ & Durum wheat & 305793 \\
\hline wPt-6643 & 45.84 & $4 A^{m}$ & $2 B$ & Durum wheat & 373941 \\
\hline wPt-8897 & 65.87 & $4 A^{m}$ & $7 \mathrm{~A}$ & Bread wheat & 116046 \\
\hline wPt-237I & 127.59 & $4 A^{m}$ & $7 A$ & A-Genome & 376548 \\
\hline wPt-|26| & 21.8 & $5 A^{m}$ & $5 B \mid 5 D$ & Bread wheat & 120208 \\
\hline wPt-2707 & 78.22 & $5 \mathrm{~A}^{\mathrm{m}}$ & $5 B$ & Bread wheat & 120752 \\
\hline wPt-4577 & 78.7I & $5 A^{m}$ & $5 B$ & Bread wheat & 116733 \\
\hline wPt-8920 & 79.54 & $5 A^{m}$ & $7 B$ & Bread wheat & I I 6434 \\
\hline wPt-3425 & 121.62 & $5 A^{m}$ & $7 A$ & Durum wheat & 380762 \\
\hline wPt-309I & 29.23 & $6 \mathrm{~A}^{\mathrm{m}}$ & $6 \mathrm{~A}$ & Bread wheat & 116120 \\
\hline wPt-8833 & 29.26 & $6 \mathrm{~A}^{\mathrm{m}}$ & $6 \mathrm{~A} \mid 6 \mathrm{~B}$ & Bread wheat & 115618 \\
\hline wPt-7063 & 61.3 & $6 \mathrm{~A}^{\mathrm{m}}$ & $6 \mathrm{~A}^{\prime}$ & Bread wheat & 115260 \\
\hline wPt-0562 & 113.39 & $6 \mathrm{~A}^{\mathrm{m}}$ & $6 \mathrm{~A}$ & Durum wheat & 345110 \\
\hline wPt-3468 & 113.93 & $6 \mathrm{~A}^{\mathrm{m}}$ & $6 \mathrm{~A}$ & Bread wheat & 116359 \\
\hline wPt-2582 & 121.36 & $6 \mathrm{~A}^{\mathrm{m}}$ & $6 \mathrm{~A}$ & A-Genome & 376551 \\
\hline wPt-3107 & 38.13 & $7 A^{m}$ & $3 B$ & Bread wheat & 116406 \\
\hline wPt-3393 & 68.69 & $7 A^{m}$ & $7 A$ & Bread wheat & $11970 \mid$ \\
\hline wPt-3964 & 71.2 & $7 A^{m}$ & $7 A$ & Durum wheat & 305423 \\
\hline wPt-2044 & 71.29 & $7 A^{m}$ & $7 A$ & Durum wheat & 305067 \\
\hline wPt-4748 & 71.48 & $7 A^{m}$ & $7 A$ & Bread wheat & 115379 \\
\hline rPt-4I99 & 71.48 & $7 A^{m}$ & $7 A$ & Durum wheat & 347395 \\
\hline wPt-728I & 93.37 & $7 A^{m}$ & $|A| 7 A$ & Durum wheat & 343649 \\
\hline wPt-43I 9 & 125.75 & $7 A^{m}$ & $7 B \mid 7 D$ & A-Genome & 376425 \\
\hline wPt-7763 & 125.99 & $7 A^{m}$ & 7A|7D & Bread wheat & 116340 \\
\hline wPt-I359 & 126.04 & $7 A^{m}$ & $7 B \mid 7 D$ & A-Genome & 376448 \\
\hline wPt-9877 & 126.42 & $7 A^{m}$ & $7 \mathrm{~B}$ & Durum wheat & 346285 \\
\hline wPt-I533 & 129.34 & $7 A^{m}$ & $7 B$ & Bread wheat & II 7080 \\
\hline wPt-5069 & 129.4 & $7 A^{m}$ & $7 B$ & Bread wheat & 116930 \\
\hline$w P t-6320$ & 129.67 & $7 A^{m}$ & $7 B$ & Bread wheat & 116539 \\
\hline
\end{tabular}



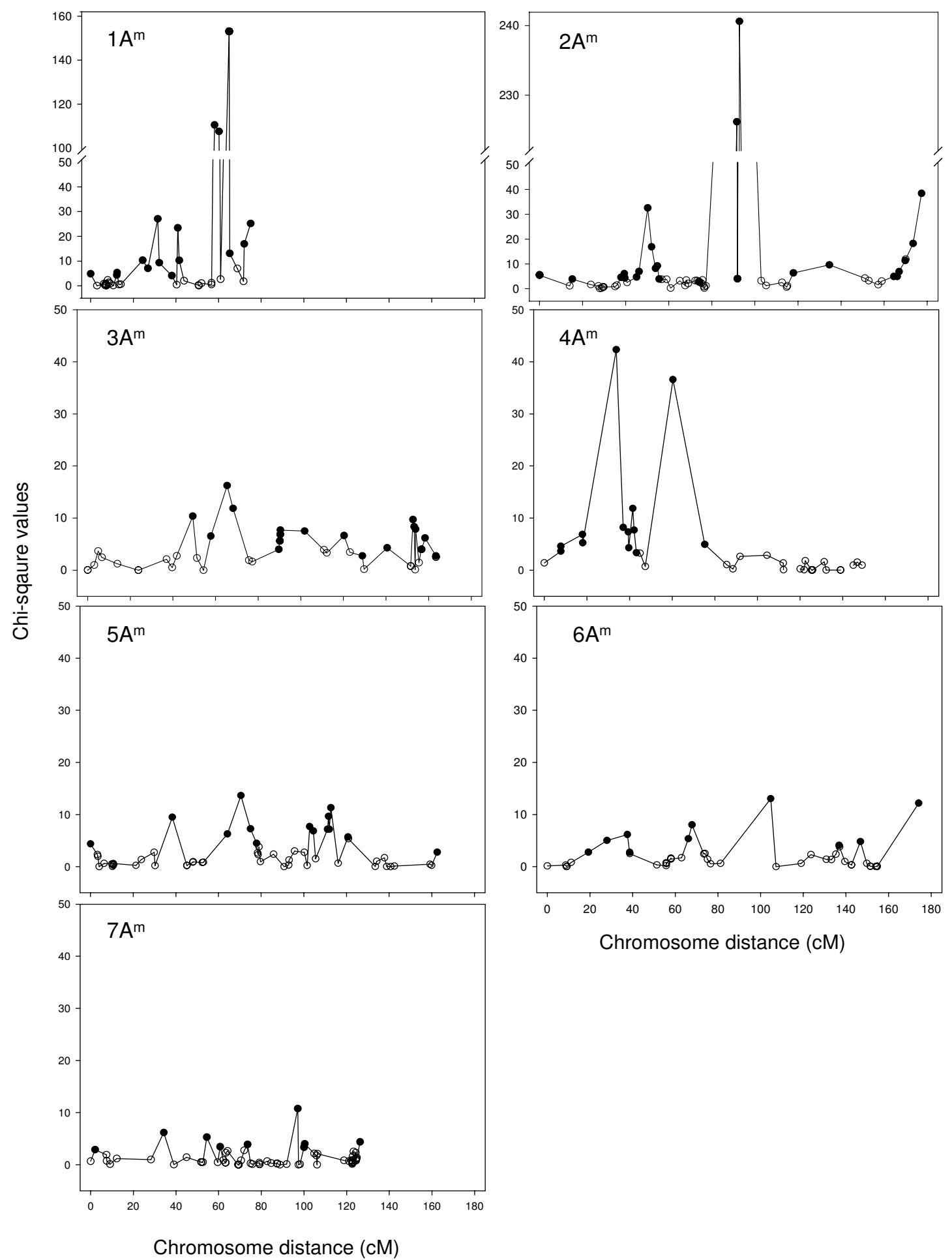

Chromosome distance (cM)

Figure 6

The distribution of $\chi^{2}$ values for individual DArT and SSR loci as a function of the genetic linkage map along the chromosomes in T. monococcum. The genetic loci with open symbols fit 1:2:I or I:3 ratios of allele segregation frequencies, whereas those with close symbols showed segregation distortion. 
PCR products were diluted to 20-40 times using formamide Li-Cor loading dye, denatured for $5 \mathrm{~min}$ at $85^{\circ} \mathrm{C}$ and stored on ice before $0.5-0.8 \mu 1$ of the reaction mix was loaded on Li-Cor 4300 DNA Analyser.

\section{T. monococcum accession diversity analysis and comparison with hexaploid wheat}

A group of $16 \mathrm{~T}$. monococcum accessions were genotyped using the custom-built DArT array as described previously [36]. The polymorphic DArT markers were scored, and used for clustering analysis using principal coordinate plots. For genome comparison, genome representations of nine T. monococcum accessions and 23 hexaploid wheat varieties were hybridised to a newly built DArT array and scored the same way. The ploidy levels did influence the scoring as envisaged in the raw data of the hybridisation intensity. Therefore, only the DArT markers which were not affected by this context-dependent scoring were scored. The nine T. monococcum accessions and 23 hexaploid wheat varieties were hybridised in duplicate.

\section{Genetic mapping and integration of DArT and SSR markers}

T. monococcum accessions MDR308, MDR002 and $94 \mathrm{~F}_{2}$ individuals derived from a cross between them were genotyped with the custom-built array as described previously [36]. In total, 300 DArT markers, 90 SSR markers as well as two morphological trait loci ( $\mathrm{Ba}$, black awn; $\mathrm{Hl}$, hairy leaf) were used for genetic linkage map construction using JoinMap ${ }^{\circledR} 4.0$ (Van Ooijen, J.W., 2006, JoinMap ${ }^{\circledR}$ 4.0, Software for the calculation of genetic linkage maps in experimental populations. Kyazma B. V., Wageningen, The Netherlands). Because of the inherent dominant nature of DArT markers which separates the female and male markers in the repulsion phase, the linkage maps for maternal DArT markers (scored as $a, c$ ) and for parental DArT markers (scored as $b, d$ ) were initially constructed independently with SSR markers. The two maps for individual chromosomal linkage groups were then merged together using SSR markers as bridges. Assignment of markers to linkage groups was achieved using logarithm of the odds (LOD) threshold values ranging from 3.0 to 10.0. The Kosambi's map function was used to estimate genetic distances. In total, 358 markers including 274 DArT markers, 82 SSR markers and 2 morphological trait locus markers were integrated into nine linkage groups. Goodness of fit for all the loci to an expected 1:2:1 or 1:3 segregation ratio was tested using chi-square $\left(\chi^{2}\right)$ analysis. The graphical representation of the map was drawn using GGT2.2 software [64].

\section{Statistical analysis}

All statistical analyses were carried out using GenStat $\left(10^{\text {th }}\right.$ edition, VSN International, UK). For principal coordinate analysis Jaccard similarity matrices were generated using the DArT markers. Two-dimensional scores were calculated and used to generate scatter plot matrices of scores. For the Mantel test which looks for association between the off-diagonal values of two similarity (or distance) matrices, the correlation of the matrices were evaluated. The DArT markers were subdivided into four different categories depending on their genome origins and similarity matrices calculated. The similarity coefficients from these matrices were then compared pair by pair to form a new correlation matrix. The significance of each correlation was assessed using a randomisation test (with 1000 random permutations). The $p$-values were calculated and were always $<0.001$ (where the null hypothesis is one of zero association). For the Kolmogorov-Smirnov test, the map position data of the DArT and SSR markers on individual chromosomes were fed into GenStat and the p-values were calculated. The Chi-square goodness-of-fit test was carried out to examine the random distribution of DArT markers of different origins across the genome, by calculating the association between the numbers of the markers of different origins the chromosomes.

\section{Data deposition}

The genetic marker and linkage map data, along with details and accession numbers for the deposition of raw data, are freely available at the UK WGIN http:// www.WGIN.org.uk and Monogram http://www.monogram.ac.uk/services.php as well as the GrainGene http:// wheat.pw.usda.gov/GG2/index.shtml websites.

\section{Competing interests}

Employees of DArT PL co-authoring this paper (AK, EH and PW) provide DArT array commercial genotyping services for a range of crops and may benefit financially from this work.

\section{Authors' contributions}

All authors read and approved the final manuscript. KHK, HCJ and AK designed the study and coordinated the research activities. HCJ, KHK and KK drafted the manuscript. HCJ, CB, KK and SB developed SSR markers for Triticum monococcum. PW, EH and AK developed the DArT array for T. monococcum, mapped DArT markers, and edited the manuscript. KHK raised the funds, initiated and supervised the whole project.

\section{Additional material}

\section{Additional file 1}

The 15 Iranian accessions of Triticum boeoticum used to generate the customised DArT array used in this study.

Click here for file

[http://www.biomedcentral.com/content/supplementary/14712164-10-458-S1.doc] 


\section{Additional file 2 \\ Hexaploid wheat varieties used in comparative analysis using DArT mark- ers. \\ Click here for file \\ [http://www.biomedcentral.com/content/supplementary/1471- 2164-10-458-S2.doc]}

\section{Acknowledgements}

This research is part of the core project of the Wheat Genetic Improvement Network which is supported by a grant from the Department for Environment, Food and Rural Affairs (Defra, AR0709). The Li-Cor 4300 DNA analysers were purchased with funds received from a BBSRC - REI grant (BB/C5III056/I). The hexaploid wheat genotypes selected for analysis were part of either the BBSRC-CASE studentship (BB/S/N/2002/846) awarded to KHK or the EU-FP6 Integrated Project BIOEXPLOIT (partner $007 \mathrm{KHK}$ ). We thank Dr. Sue Welham for her excellent statistical advice. We thank Daniel Jenk and Kim Oldham for their technical support in verifying SSR work. Rothamsted Research receives grant-aided support from the Biotechnology and Biological Sciences Research Council (BBSRC) of the UK.

\section{References}

I. Heun M, Schäfer-Pregl R, Klawan D, Castagna R, Accerbi M, Borghi B, Salamini F: Site of einkorn wheat domestication identified by DNA fingerprinting. Science |997, 278(534|):|3|2-|3|4.

2. Zohary D, Hopf M: Domestication of plants in the Old World: The origin and spread of cultivated plants in West Asia Europe, and the Nile Valley. 2nd edition. New York: Oxford University Press; 1993; 1993.

3. Kilian B, Ozkan H, Walther A, Kohl J, Dagan T, Salamini F, Martin W: Molecular diversity at 18 loci in 321 wild and 92 domesticate lines reveal no reduction of nucleotide diversity during Triticum monococcum (Einkorn) domestication: implications for the origin of agriculture. Mol Biol Evol 2007, 24(I 2):2657-2668.

4. Wicker T, Yahiaoui N, Guyot R, Schlagenhauf E, Liu Z-D, Dubcovsky J, Keller B: Rapid genome divergence at orthologous low molecular weight glutenin loci of the $A$ and $A^{m}$ genomes of wheat. Plant Cell 2003, I 5(5): I I86- I I 97.

5. Huang S, Sirikhachornkit A, Su X, Faris J, Gill B, Haselkorn R, Gornicki $P$ : Genes encoding plastid acetyl-CoA carboxylase and 3phosphoglycerate kinase of the Triticum/Aegilops complex and the evolutionary history of polyploid wheat. Proc Natl Acad Sci USA 2002, 99(1 2):8133-8138.

6. Dvorak J, Yang ZL, You FM, Luo MC: Deletion polymorphism in wheat chromosome regions with contrasting recombination rates. Genetics 2004, I 68(3): 1665-1675.

7. James RA, Davenport RJ, Munns R: Physiological characterization of two genes for $\mathrm{Na}+$ exclusion in durum wheat, $\mathrm{Nax}$ and Nax2. Plant Physiol 2006, I 42(4): I 537-I 547.

8. Jing HC, Kornyukhin D, Kanyuka K, Orford S, Zlatska A, Mitrofanova $\mathrm{OP}$, Koebner R, Hammond-Kosack K: Identification of variation in adaptively important traits and genome-wide analysis of trait-marker associations in Triticum monococcum. J Exp Bot 2007, 58(13):3749-3764.

9. Jing HC, Lovell D, Gutteridge R, Jenk D, Kornyukhin D, Mitrofanova OP, Kema GH, Hammond-Kosack KE: Phenotypic and genetic analysis of the Triticum monococcum-Mycosphaerella graminicola interaction. New Phytol 2008, I 79(4): I I 2 I-I I 32.

10. Feuillet C, Travella S, Stein N, Albar L, Nublat A, Keller B: Mapbased isolation of the leaf rust disease resistance gene Lr 10 from the hexaploid wheat (Triticum aestivum L.) genome. Proc Natl Acad Sci USA 2003, I 00(25): I 5253-I5258.

II. Stein N, Feuillet C, Wicker T, Schlagenhauf E, Keller B: Subgenome chromosome walking in wheat: a 450-kb physical contig in Triticum monococcum $L$. spans the Lrl 0 resistance locus in hexaploid wheat (Triticum aestivum L.). Proc Natl Acad Sci USA 2000, 97(24): | 3436-|344|.
12. Yan L, Loukoianov A, Tranquilli G, Helguera M, Fahima T, Dubcovsky J: Positional cloning of the wheat vernalization gene VRNI. Proc Natl Acad Sci USA 2003, I 00( I 0):6263-6268.

13. Yan L, Helguera M, Kato K, Fukuyama S, Sherman J, Dubcovsky J: Allelic variation at the VRN-I promoter region in polyploid wheat. Theor Appl Genet 2004, I09(8): I677-I686.

14. Faris JD, Fellers JP, Brooks SA, Gill BS: A bacterial artificial chromosome contig spanning the major domestication locus $Q$ in wheat and identification of a candidate gene. Genetics 2003, I64(I):3||-32|.

I5. Simons KJ, Fellers JP, Trick HN, Zhang Z, Tai YS, Gill BS, Faris JD: Molecular characterization of the major wheat domestication gene Q. Genetics 2006, I 72(I):547-555.

16. Uauy C, Distelfeld A, Fahima T, Blechl A, Dubcovsky J: A NAC Gene regulating senescence improves grain protein, zinc, and iron content in wheat. Science 2006, 3 I 4(5803): I 298- I $30 \mid$

17. Bullrich L, Appendino ML, Tranquilli G, Lewis S, Dubcovsky J: Mapping of a thermo-sensitive earliness per se gene on Triticum monococcum chromosome IA(m). Theor Appl Genet 2002, I 05(4):585-593.

18. Kuraparthy V, Sood S, Dhaliwal HS, Chhuneja P, Gill BS: Identification and mapping of a tiller inhibition gene (tin3) in wheat. Theor Appl Genet 2007, I | 4(2):285-294.

19. Castagna R, Maga G, Perenzin M, Heun M, Salamini F: RFLP-based genetic relationships of einkorn wheats. Theor Appl Genet 1994 88(6-7):818-823.

20. Dubcovsky J, Luo M-C, Dvorak J: Differentiation between homoeologous chromosomes I A of wheat and I A-m of Triticum monococcum and its recognition by the wheat $\mathrm{Ph} I$ locus. Proc Natl Acad Sci USA 1995, 92(14):6645-6649.

21. Dubcovsky J, Luo M-C, Zhong G-Y, Bransteitter R, Desai A, Kilian A Kleinhofs A, Dvorak J: Genetic map of diploid wheat, Triticum monococcum L., and its comparison with maps of Hordeum vulgare L. Genetics 1996, I43(2):983-999.

22. Luo MC, Deal K, Yang ZL, Dvorak J: Comparative genetic maps reveal extreme crossover localization in the Aegilops speltoides chromosomes. Theor Appl Genet 2005 , I I | (6): | 098- I I06.

23. Faris JD, Zhang Z, Fellers JP, Gill BS: Micro-colinearity between rice, Brachypodium, and Triticum monococcum at the wheat domestication locus Q. Funct Integr Genomics 2008, 8(2): I 49- I64.

24. Singh K, Ghai M, Garg M, Chhuneja P, Kaur P, Schnurbusch T, Keller $B$, Dhaliwal HS: An integrated molecular linkage map of diploid wheat based on a Triticum boeoticum $\times$ T. monococcum RIL population. Theor Appl Genet 2007, I I 5(3):30 I-3 I 2

25. Hammer K, Filatenko AA, Korzun V: Microsatellite markers - a new tool for distinguishing diploid wheat species. Genet Resour Crop Evol 2000, 47(5):497-505.

26. Podlich DW, Winkler CR, Cooper M: Mapping as you go: An effective approach for marker-assisted selection of complex traits. Crop Sci 2004, 44(5): |560-|57|.

27. Jaccoud D, Peng K, Feinstein D, Kilian A: Diversity arrays: a solid state technology for sequence information independent genotyping. Nucleic Acids Res 200I, 29(4):E25.

28. Wenzl P, Carling J, Kudrna D, Jaccoud D, Huttner E, Kleinhofs A, Kilian A: Diversity Arrays Technology (DArT) for wholegenome profiling of barley. Proc Natl Acad Sci USA 2004, I0 I (26):9915-9920.

29. Hearnden PR, Eckermann PJ, McMichael GL, Hayden MJ, Eglinton JK, Chalmers KJ: A genetic map of I,000 SSR and DArT markers in a wide barley cross. Theor Appl Genet 2007, I I 5(3):383-39I.

30. Wenzl P, Li H, Carling J, Zhou M, Raman H, Paul E, Hearnden P, Maier C, Xia L, Caig V, et al.: A high-density consensus map of barley linking DArT markers to SSR, RFLP and STS loci and agricultural traits. BMC Genomics 2006, 7:206.

31. Wenzl P, Raman H, Wang J, Zhou M, Huttner E, Kilian A: A DArT platform for quantitative bulked segregant analysis. $B M C$ Genomics 2007, 8:196.

32. Wittenberg $A H$, Lee $T$ van der, Cayla $C$, Kilian A, Visser RG, Schouten HJ: Validation of the high-throughput marker technology DArT using the model plant Arabidopsis thaliana. Mol Genet Genomics 2005, 274(I):30-39.

33. Xia L, Peng K, Yang S, Wenzl P, de Vicente MC, Fregene M, Kilian A DArT for high-throughput genotyping of Cassava (Manihot esculenta) and its wild relatives. Theor Appl Genet 2005, I I 0(6): 1092-1098. 
34. Mace ES, Xia L, Jordan DR, Halloran K, Parh DK, Huttner E, Wenzl P, Kilian A: DArT markers: diversity analyses and mapping in Sorghum bicolor. BMC Genomics 2008, 9:26.

35. Akbari M, Wenzl P, Caig V, Carling J, Xia L, Yang S, Uszynski G, Mohler $V$, Lehmensiek A, Kuchel $H$, et al.: Diversity arrays technology (DArT) for high-throughput profiling of the hexaploid wheat genome. Theor Appl Genet 2006, I I 3(8): |409-| 420.

36. Peleg Z, Saranga Y, Suprunova T, Ronin Y, Roder MS, Kilian A, Korol $A B$, Fahima $T$ : High-density genetic map of durum wheat $\times$ wild emmer wheat based on SSR and DArT markers. Theor Appl Genet 2008, I I 7(I): I03-II5.

37. Semagn K, Bjornstad A, Skinnes H, Maroy AG, Tarkegne $Y$, William $M$ : Distribution of DArT, AFLP, and SSR markers in a genetic linkage map of a doubled-haploid hexaploid wheat population. Genomes 2006, 49(5):545-555.

38. White J, Law JR, MacKay I, Chalmers KJ, Smith JS, Kilian A, Powell W: The genetic diversity of UK, US and Australian cultivars of Triticum aestivum measured by DArT markers and considered by genome. Theor Appl Genet 2008, I I 6(3):439-453.

39. James KE, Schneider H, Ansell SW, Evers M, Robba L, Uszynski G, Pedersen N, Newton AE, Russell SJ, Vogel JC, et al.: Diversity arrays technology (DArT) for pan-genomic evolutionary studies of non-model organisms. PLoS ONE 2008, 3(2):e I682.

40. Cox TS, Harrell LG, Chen P, Gill BS: Reproductive behavior of hexaploid-diploid wheat hybrids. Plant Breed I99I, 107(2): $105-118$

4I. Jacobs AS, Pretorius JA, Kloppers FJ, Cox TS: Mechanisms associated with wheat leaf rust resistance derived from Triticum monococcum. Phytopathology 1996, 86(6):588-595.

42. Korzun V, Röder M, Ganal M, Hammer K, Filatenko A: Genetic diversity and evolution of the diploid wheats $T$. urartu, $T$. boeoticum and $T$. monococcum revealed by microsatellite markers. Schr Genet Ressour 1998, 8:244-247.

43. Mantel N: The detection of disease clustering and a generalized regression approach. Cancer Res 1967, 27(2):209-220.

44. Somers DJ, Isaac P, Edwards K: A high-density microsatellite consensus map for bread wheat (Triticum aestivum L.). Theor Appl Genet 2004, I09(6): I I05- I I I4.

45. Varshney RK, Langridge P, Graner A: Application of genomics to molecular breeding of wheat and barley. Adv Genet 2007, 58: $12|-| 55$

46. Luo MC, Yang ZL, Kota RS, Dvorak J: Recombination of chromosomes $3 A(\mathrm{~m})$ and $5 A(\mathrm{~m})$ of Triticum monococcum with homeologous chromosomes $3 A$ and $5 A$ of wheat: the distribution of recombination across chromosomes. Genetics 2000 I 54(3): I 30|-| 308.

47. Chantret N, Cenci A, Sabot F, Anderson O, Dubcovsky J: Sequencing of the Triticum monococcum hardness locus reveals good microcolinearity with rice. Mol Genet Genomics 2004, 27 I (4):377-386.

48. Chantret N, Salse J, Sabot F, Rahman S, Bellec A, Laubin B, Dubois I, Dossat C, Sourdille $P$, Joudrier $P$, et al.: Molecular basis of evolutionary events that shaped the hardness locus in diploid and polyploid wheat species (Triticum and Aegilops). Plant Cell 2005, I 7(4): I033-1045.

49. Torada A, Koike M, Mochida K, Ogihara $Y$ : SSR-based linkage map with new markers using an intraspecific population of common wheat. Theor Appl Genet 2006, I I 2(6): I042-105I.

50. Paillard S, Schnurbusch T, Winzeler M, Messmer M, Sourdille P, Abderhalden O, Keller B, Schachermayr G: An integrative genetic linkage map of winter wheat (Triticum aestivum L.). Theor Appl Genet 2003, 107(7): I235-1242.

5I. Quarrie SA, Steed A, Calestani C, Semikhodskii A, Lebreton C, Chinoy C, Steele N, Pljevljakusic D, Waterman E, Weyen J, et al.: A highdensity genetic map of hexaploid wheat (Triticum aestivum L.) from the cross Chinese Spring $\times$ SQI and its use to compare QTLs for grain yield across a range of environments. Theor Appl Genet 2005, I I 0(5):865-880.

52. Sourdille P, Cadalen T, Guyomarc'h H, Snape JW, Perretant MR Charmet G, Boeuf C, Bernard S, Bernard M: An update of the Courtot $\times$ Chinese Spring intervarietal molecular marker linkage map for the QTL detection of agronomic traits in wheat. Theor Appl Genet 2003, I 06(3):530-538.

53. Kanyuka K, Lovell DJ, Mitrofanova OP, Hammond-Kosack K, Adams MJ: A controlled environment test for resistance to Soilborne cereal mosaic virus (SBCMV) and its use to determine the mode of inheritance of resistance in wheat cv. Cadenza and for screening Triticum monococcum genotypes for sources of SBCMV resistance. Plant Pathol 2004, 53(2): I 54- I60.

54. Dubcovsky J, Luo MC, Zhong GY, Bransteitter R, Desai A, Kilian A Kleinhofs A, Dvorak J: Genetic map of diploid wheat, Triticum monococcum L., and its comparison with maps of Hordeum vulgare L. Genetics 1996, I43(2):983-999.

55. Lijavetzky D, Muzzi G, Wicker T, Keller B, Wing R, Dubcovsky J: Construction and characterization of a bacterial artificial chromosome (BAC) library for the A genome of wheat. Genome 1999, 42(6): I I76-I I82.

56. Song QJ, Shi JR, Singh S, Fickus EW, Costa JM, Lewis J, Gill BS, Ward $R$, Cregan PB: Development and mapping of microsatellite (SSR) markers in wheat. Theor Appl Genet 2005, I I 0(3):550-560.

57. Song Q], Fickus EW, Cregan PB: Characterization of trinucleotide SSR motifs in wheat. Theor Appl Genet 2002, 104(23):286-293.

58. Guyomarc'h H, Sourdille P, Charmet G, Edwards J, Bernard M: Characterisation of polymorphic microsatellite markers from Aegilops tauschii and transferability to the D-genome of bread wheat. Theor Appl Genet 2002, I 04(6-7): I I64- II 72.

59. Guyomarc'h H, Sourdille P, Edwards J, Bernard M: Studies of the transferability of microsatellites derived from Triticum tauschii to hexaploid wheat and to diploid related species using amplification, hybridization and sequence comparisons. Theor Appl Genet 2002, I 05(5):736-744.

60. Eujayl I, Sorrells ME, Baum M, Wolters P, Powell W: Isolation of EST-derived microsatellite markers for genotyping the A and B genomes of wheat. Theor Appl Genet 2002, 104(23):399-407.

6I. Roder MS, Korzun V, Wendehake K, Plaschke J, Tixier MH, Leroy P Ganal MW: A microsatellite map of wheat. Genetics 1998 , I 49(4):2007-2023.

62. Pestsova E, Ganal MW, Roder MS: Isolation and mapping of microsatellite markers specific for the $D$ genome of bread wheat. Genome 2000, 43(4):689-697.

63. Gupta K, Balyan S, Edwards I, Isaac P, Korzun V, Roder M, Gautier MF Joudrier P, Schlatter R, Dubcovsky J, et al.: Genetic mapping of $\mathbf{6 6}$ new microsatellite (SSR) loci in bread wheat. Theor Appl Genet 2002, I 05(2-3):4I3-422.

64. van Berloo R: GGT 2.0: versatile software for visualization and analysis of genetic data. J Hered 2008, 99(2):232-236.

\section{Publish with Bio Med Central and every scientist can read your work free of charge}

"BioMed Central will be the most significant development for disseminating the results of biomedical research in our lifetime. "

Sir Paul Nurse, Cancer Research UK

Your research papers will be:

- available free of charge to the entire biomedical community

- peer reviewed and published immediately upon acceptance

- cited in PubMed and archived on PubMed Central

- yours - you keep the copyright
BioMedcentral 